\title{
Generalized trust and diversity in the classroom: A longitudinal study of Romanian adolescents
}

\author{
Gabriel Bădescu
}

Paul E. Sum

University of North Dakota, paul.sum@UND.edu

How does access to this work benefit you? Let us know!

Follow this and additional works at: https://commons.und.edu/pssa-fac

\section{Recommended Citation}

Gabriel Bădescu and Paul E. Sum. "Generalized trust and diversity in the classroom: A longitudinal study of Romanian adolescents" (2015). Political Science \& Public Administration Faculty Publications. 1.

https://commons.und.edu/pssa-fac/1

This Article is brought to you for free and open access by the Department of Political Science \& Public Administration at UND Scholarly Commons. It has been accepted for inclusion in Political Science \& Public Administration Faculty Publications by an authorized administrator of UND Scholarly Commons. For more information, please contact und.commons@library.und.edu. 
Generalized trust and diversity in the classroom: a longitudinal study of Romanian adolescents

\begin{abstract}
Generalized trust, the faith we place in strangers, is a fundamental attribute of democratic societies. We investigate the development of generalized trust using data collected from Romanian high school students within a multi-level, panel research design. We find that diversity in the classroom, defined through ethnic and socio-economic differences, has negative effects on generalized trust. Associational membership interacts indirectly with diversity, counteracting the negative impact of ethnic diversity but reinforcing socio-economic distinctions. The findings support cultural theories of generalized trust and point to the potentially positive role educational policy might play in encouraging trust among youths.
\end{abstract}

Keywords: generalized trust, diversity, adolescents, Romania 
Generalized trust is the faith you place in people who you do not know. Trusting strangers increases the possibilities that groups will overcome collective action problems and encourages cooperative behavior among people who do not otherwise have a relationship (Coleman 1990; Newton 1999; Putnam 1993; Uslaner 2002). In addition, generalized trust has been shown to serve as a bond that enhances social cohesion, bringing and keeping people together with a sense of community (Marschall and Stolle 2004; Putnam 2000; Uslaner 2002; Woolcock 2001). Generalized trust contributes to a host of other desirable outcomes such as encouraging of norms of reciprocity, tolerance, and civic morality, all of which are necessary features of good governance under democratic institutions (Letki 2006; Sullivan and Transue 1999). Beyond good citizenship, improvements in group task orientation and completion are additional dividends associated with generalized trust (Colquitt, et al. 2007).

In the early stages of post-communist democratization in Eastern Europe, levels of generalized trust were low relative to Western countries. Evidence suggests that legacies of the former regimes (Newton 1999; Uslaner 1999; Völker and Flap 2003) and effects from the transition itself (Letki and Evans 2005; Muller and Seligson 1994) account for this poor starting position. However, levels of generalized trust have not caught up despite expectations that they would, and Romania has been emblematic of this trend (Delhey and Newton 2005; Voicu 2005).

The present study attempts to contribute to an explanation for the persistence of low generalized trust in Romania. Evidence suggests that within contexts of diversity, generalized trust is difficult to develop (Dinesen and Sønderskov 2012). We test this assertion among Romanian high school students. Using panel data, we estimate the impact of two forms of diversity: ethnic diversity and income diversity. Most studies that have considered the impact of ethnic diversity are concerned with diversity as manifested through an immigrant population interacting with a 
historically homogeneous host population (e.g. Dinesen 2011). Diversity in Romania is characterized as the interaction among the ethnic Romanian majority and historic minorities in the country: ethnic Hungarians and Roma. Thus, our study expands the notion of ethnic diversity usually analyzed as a factor influencing generalized trust. We also expand the notion of diversity to include socio-economic differences. For post-communist cases, income disparities may not be larger than those in Western Europe but with income levels substantially lower, income differences are more salient because so many more people live close to or under the poverty line. The impact of income inequality on trust has been studied at a society-level (e.g. Uslaner 2002) and at the neighborhood level (e.g. Leigh 2006). We consider this on at the more intimate level of the classroom.

Although parents clearly provide the strongest force in childhood attitudinal development, schools are an important setting for how those attitudes further develop and become applied in the absence of direct parental influence (Andolina et al. 2003; Niemi and Sobieszek 1977). In addition, relationships between ethnic diversity and out-group relations are more likely to be found at the mezzo level of analysis, in this case the school (Dinesen 2011; Forbes 1997). Educational institutions may hold the key to reversing the trend of mistrust since education is at the foundation of a universal welfare state (Rothstein and Uslaner 2005, 72). Therefore, the context provides opportunities for policy intervention.

\section{Conceptualizing and measuring trust}

Generalized trust, or faith that we place in strangers, is analytically distinct from "knowledge-based trust," which requires information about a person before we trust him or her (Yamagishi and Yamagishi, 1994). For knowledge-based trust, information might be based on 
frequent contact with people we know well, for example relatives, friends, or co-workers, producing strategic trust. Alternatively, information might be indirect and extend to certain attributes we share with others, such as ethnicity or religion, producing particularized trust. Generalized trust is different than either strategic or particularized trust because it does not presume prior knowledge or experience. ${ }^{1}$ Instead, generalized trust is said to serve as a bridging mechanism across social boundaries that, among other things, will transcend the negative consequences of social diversity (Putnam 2000, 22-24). Moreover, there is wide acknowledgement that generalized trust matters most for "getting things done" since it spans the broadest reaches of the moral community, and as a result, is more relevant for overcoming collective action dilemmas (Uslaner 2002).

The decision to trust strangers is more than the result of simple rational calculations based on past experiences when others were trustworthy (Aumann and Dreze 2005). Rather, generalized trust is more likely the result of a blending of direct and indirect experience, knowledge about norms of behavior, and a fundamental attitudinal disposition (Jefferies 2002, 133; Frietag and Traunmüller 2009). This personality-based form of trust has been referred to by scholars as moral trust (Uslaner 2002; 2006), dispositional trust (Kramer, 1999), generalized trust (Dinesen 2010), and trust propensity (Mayer et al., 1995), all of which create a filter that alters one's interpretations of others' actions. In this way, our own observations are "theory-laden” (Grovier 1994, 174). Thus, people who are trusting retain the dispositional component of generalized trust even after trustworthiness can be inferred. Colquitt, et al. (2007) show through meta-analysis that trust propensity is the key driver of a cognitive "leap" beyond the expectations that reason and

\footnotetext{
${ }^{1}$ For a full discussion of the distinctions among strategic, particularized, and generalized trust, see Uslaner (2002, ch.3)
} 
experience alone would warrant, affecting the trust decision independently from other information that would suggest trustworthiness.

Measuring generalized trust is anything but straightforward. Survey-based studies of generalized trust normally use as their measurement instrument the question, "Generally speaking, would you say that most people can be trusted or that you can't be too careful in dealing with people?" The responses are recorded either on a binary scale, such as the General Social Survey or the World Values Survey, or on an 11-point Likert scale, such as the European Social Survey. Several validity problems are associated with these variants of the trust question since it leaves a number of crucial interpretations to respondents. If trust is considered as a relationship where $A$ trusts some specific $B$ with respect to some specific $x$, the commonly-used trust questions are underspecified. Respondents must fill in their own specifications, which may or may not vary among individual respondents or groups of respondents. ${ }^{2}$

Assessments of measurement validity with regard to the standard survey-based trust questions focus on the equivocacy of the "most people" frame. Making reference to most people when asking about generalized trust may unintentionally lead respondents to think about the trust they have in people like them, not strangers who transcend lines of social diversity (Reeskens and Hooghe, 2002; Delhey and Newton, 2005). At the same time, the standard question of generalized trust likely elicits responses regarding the extent to which the respondent perceives another as a member of one's self-defined "moral community" (Uslaner 2002). This community could include mostly people who are similar to the respondents, or could be broader, including people about whom the respondent has no information. If the inclusiveness or exclusiveness of people's moral communities varies, this makes responses difficult to compare. If the variance includes how one

\footnotetext{
${ }^{2}$ Another approach in the study of diversity is to use a measure of trust that is experiential and more likely to be affected by context (see for instance Stolle, et al. 2008).
} 
evaluates trust in a context of social diversity, then we should expect diverging findings as to the effects of a diverse context on generalized trust.

Previous studies on Romania have found that the questions asking about the level of trust respondents have in people of a different ethnicity and people of a different religion are strongly correlated with a latent variable of generalized trust, the type of trust referring to a broad "moral community." Whereas trust in family members, in people of the same ethnicity, and in people of the same religion correlate more to the variable of knowledge-based trust and much less with trust in strangers (Bădescu 2003). For our analysis, we measure generalized trust among Romanian adolescents as a composite of trust in strangers, people of other religions, and people of other ethnicities. ${ }^{3}$ Crombach's Alpha for these components is 0.68 in each of the two waves of Panel 1 , and 0.67 for each of the two waves in Panel 2. Thus, we are confident that the three dimesnions contribute to a common syndrome, and that the syndrome reflects the perceptions of moral community in Romania.

\section{Exposure to diversity and generalized trust}

Besides its conceptualization, the extent to which generalized trust is malleable continues to be debated (Nannestad 2008). Do we trust strangers based on, at least in part, our assessment of the people to whom and contexts to which we are exposed? Experiential theories, which emphasize how individual trust in the generalized other is formed by experiences in the environment, respond affirmatively (Dinesen, 2010; Glanville and Paxton, 2007). Alternatively, cultural theories posit generalized trust as a stable character trait formed early in life by cultural transmission and largely

\footnotetext{
${ }^{3}$ Given the dominance of Romanian ethnics ( 89.5 percent) who practice Orthodox Christianity ( 86.8 percent), trusting people of different ethnicities and religious faiths speaks to a broader moral community in the abstract, which relates to perceptions of strangers.
} 
immune to later influences (Uslaner, 2002). The primary influence is parents, but schools and other cultural institutions play a role in shaping these early impressions.

We expect generalized trust to follow the pattern of other political attitudes: variable adolescents who are exposed to an odyssey of new experiences (Jennings and Niemi 1974; 1981). However, the degree of variance is unclear. Experiential theories predict that generalized trust will be highly variable due to the volume and range of experiences to which high school students are exposed. Cultural theory proponents expect minimal variance, since high school students' sense of moral reasoning is already developed for the most part. In either case, whether high or low variance, we still confront a problem of identifying the causal factors within a particular context. We consider the effect of diverse settings on the impact of generalized trust among high school students. Thus, we estimate the mezzo effects of classroom diversity on trust.

Contact theory maintains that diverse contexts, such as the ethnic or class make-up of one's class colleagues, facilitates positive out-group interactions that will reduce social conflict (Allport 1954; Bobo and Tuan 2006; Dovidio and Gaertner 1999; Tajfel and Turner 1986). Through social interaction, distinctions between in-groups and out-groups erode and out-group solidarity becomes enhanced, thus lowering tendencies toward exclusion such as ethnocentrism, and increasing the propensity to trust not only those with whom you interact but the broader, diverse, community to which you all belong. However, while social conflict may be abated, generalized trust is not necessarily advanced in diverse contexts. Dinesen and Sønderskov (2012) find that that exposure to ethnically diverse neighborhoods may erode generalized trust. Uslaner (2002) shows that heightened income inequality is associated with declining levels of generalized trust.

Homophily provides an alternative theoretical framework for understanding the relationship between exposure to diversity and generalized trust. Homophily refers to the tendency 
for individuals to be more comfortable around people like themselves (Alesina and Ferrara 2005; Forbes 1997; Messick and Kramer 2001). By extension, we expect people operate within relatively homogeneous contexts will have less faith in strangers generally in favor of trusting those who exhibit these qualities of social comfort.

The foci, or elements of perceived sameness, can take a variety of forms. McPherson and Smith-Lovin $(1987,370)$ discuss the division between objective (homophily as similarity) and subjective (homophily as homogeneity) characteristics. The former refers to superficial assessments of others based on socially-constructed characteristics such as age, gender, ethnicity, and social status (Coleman 1990; Lazarsfeld and Merton 1954). If "similarity" through homophily is valid, we expect individuals to base generalized trust on social congruence to others in a community, or in our case, a classroom. Homophily as homogeneity, relaxes the importance of physical attributes in favor of mutual expectations among individuals. Network analysis shows that under many circumstances, individuals gravitate toward people like themselves, in an effort to "best guess" who would be the most productive partners and team members in collective endeavors (McPherson, et al. 2001). The largely sub-conscious gravitational pull may transcend socially constructed categories, and especially when one perceives signals of low social conflict and dense social networks irrespective of social status, people expect trustworthy behavior and reciprocate based on this expectation (Öberg, et al. 2009). Relevant social attributes are thus more abstract, for example a shared commitment to values associated with cosmopolitanism.

With either, similarity or homogeneity, homophily theory predicts that people will be more comfortable with individuals who possess shared characteristics, and thus be more trusting of them. The tendency, in turn, will likely reinforce perceptions that lines of cultural or social diversity are relevant distinctions. As a result, from the perspective of homophily, diverse contexts 
are expected to produce little generalized trust and may even contribute to a decrease in its level. We generate the following hypotheses based on these assertions:

H1: Students in classrooms that exhibit ethnic diversity will have lower levels of generalized trust.

H2: Students in classrooms that exhibit higher levels of income inequality will have lower levels of generalized trust.

Adolescents are exposed to many other socialization agents and contexts beyond the classroom. Although our data are limited, we test the extent to which membership in volunteer organizations might have on generalized trust. A host of studies have hypothesized a positive relationship between membership and generalized trust (e.g. Putnam 1993). However, evidence from Romania shows that active membership is the actual causal mechanism and includes far fewer members of the non-governmental sector (Bădescu, et al. 2004). Furthermore, associational life is often dominated by homogeneity and thus, membership reinforces tendencies toward homophily (McPherson and Smith-Lovin 1987, 377). Thus, we also consider how membership to voluntary associations indirectly impacts the relationship between exposure to diversity and generalized trust.

\section{Research design and methodology}

Our primary question concerns the impact that exposure to diversity in the classroom (an environmental feature on the mezzo-level) has on generalized trust (an individual attitudinal attribute). Analyses that take into account the individual-contextual interplay between generalized trust and diversity trust face distinct limits when they use data with high levels of aggregation (e.g. 
Putnam 2007). We know that the societal-level context seldom captures one's relevant experience of "community." Rather, encounters with neighbors and peers operate on a lower level of aggregation; these interpersonal interactions overshadow the broader community or even locality dimensions of social life (Dinesen and Sønderskov 2012). Thus, exposure to diversity must capture one's relevant experiences.

With these challenges in mind, we employ a multi-level panel design so that our analysis is attuned to capture changes in individual levels of generalized trust over time and model these changes according to individual and intermediate (mezzo) level characteristics. The mezzo level context we consider is the classroom, developing variables that estimate diversity among classmates. The data allow us to test several theoretical propositions that operate on the intermediate level of social life, such as the change in a student's propensity to trust strangers from time $_{1}$ (the beginning of the school year) to time 2 (the end of the school year) after being exposed to a certain level of diversity in a classroom for approximately eight months.

Commissioned by the Soros Foundation-Romania and conducted by Totem Communications, the data was collected between October 2010 and May 2011. The panel sample is national in scope and was drawn through a random process stratified by type of school (high school and vocational school), cultural region, and locality size (rural, urban $<100,000$, and urban > 100,000). The initial selection unit was a first-year class within a school. Once a class was selected, all students in that class were asked to respond. The sample resulted in 2023 respondents, representing 45 classes (schools) from 36 localities with an average school size of approximately 500 enrolled students. The data are representative of ethnic Romanian high school 
students. ${ }^{4}$ The mean number of respondents per class is 24 (median $\left.=25\right)$. The response rate was 80.2 percent.

Generalized trust is measured on an 11-point Likert scale allowing us to observe variance from time 1 to time2. To compute ethnic diversity, we aggregate self-reported ethnicity responses at the classroom level. Ethnic diversity is measured as the proportion of non-ethnic Romanians in the respondent's school class. The process resulted in 48 percent of the ethnic Romanians were in classes with at least one non-ethnic Romanian, and nine percent of respondents were in a class that included more than 10 percent non-ethnic Romanian colleagues. We operationalized socioeconomic diversity in a similar manner. We calculated the standard deviation of family income for the classroom and assigned this figure to each respondent from that classroom. Finally, our model includes household income of respondents as a control variable in the model.

[Figure 1 about here]

We use structural equations models (SEM) for the analysis. Our analysis includes eight variables: ethnic diversity (classroom level), ethnic diversity (community level), income inequality (classroom level), income inequality (community level), income of parents, institutional trust, internet use, and volunteering. Figure 1 visually represents the truncated conceptual model that includes our variables of interest. Each variable showed statistical significance when run in the full model. In the next section we conduct our data analysis and present of our findings.

\section{Data analysis}

\footnotetext{
${ }^{4}$ We include only ethnic Romanians in our sample for analysis since exposure to diversity is experienced differently from a minority point of view and we do not have enough minority respondents to support a separate model.
} 
Our analysis begins with a comparison of generalized trust measured at time ${ }_{1}$ and time 2 from the panel survey. The research design allows us to observe the extent to which generalized trust varies between the beginning of a student's high school experience (Trust 1 ) and the close of the first year (Trust2). As noted above, generalized trust is measured by latent variables that are built from three observed variables: trust in people one meets for the first time, trust in people of other ethnicities, and trust in people of other religions; high values correspond with high levels of generalized trust. Table 1 reports the percentage of students who exhibit generalized trust, for two points in time. For each component part of the index, between time ${ }_{1}$ and time 2 we see very little variance.

[Table 1 about here]

At the same time, the individual level correlation between the composite indices (Trust ${ }_{1}$ and Trust 2$)$ is $0.49(\mathrm{p}<.001)$ and mean trust correlation at the class level is $0.66(\mathrm{p}<.001)$. The finding supports the claims from proponents of cultural theories who predict that generalized trust will be relatively stable even among adolescents. This is not to say that experiences are inconsequential. However, if collective experiences shape the level of generalized trust, those experiences must be of a significant magnitude as to "speak precisely to the inclusiveness of others in our moral community" (Uslaner 2002, 37). One's initial year in secondary school would not seem to be sufficient enough in magnitude to reshape generalized trust, as suggested in Table 1. However, aggregates can be deceiving since we do not know if sub-sections of our population vary in a way that is masked with aggregates and simple correlations. With this in mind, we evaluate the extent to which generalized trust varies according to exposure to diversity. 
Table 2 describes the results of SEM analysis on generalized trust at the beginning of high school (Trust 1 ) and near the end of the student's first year (Trust 2 ). We see the stability aspect of our dependent variable with Trust 1 being the strongest predictor of Trust $2 .{ }^{5}$ The table shows estimates for the impact ethnic diversity and socio-economic diversity has on trust among ethnic Romanian young adolescents. In time ${ }_{1}$ ethnic diversity has no statistically significant effect. Measured as the level of ethnic diversity in the classroom, we see that there is no systematic impact. However, trust measured at timez shows a statistically significant negative correlation. Students from classes that are more diverse, tend to be less trusting than their counterparts who are not exposed to the same level of diversity, although the standardized regression weight is rather small at .053. Nevertheless, the finding suggests that this is a disposition acquired during the first year.

[Table 2 about here]

Table 2 reports a statistically significant, and negative, association between socioeconomic diversity at time 1 . Students entering a high school class that displays more economic diversity, as measured through the standard deviation of the class average parental income, tend to be less trusting from the beginning of their high school experience. The relationship persists to time2; however, the magnitude of the correlate is somewhat smaller at the second measurement. Table 2 also shows that the income of the respondent is not statistically significant. ${ }^{6}$

\footnotetext{
${ }^{5}$ Standardized regression weights represent the change in the dependent variable in response to a one-unit change in the independent variable. They are useful for comparing the magnitude of effect among different variables in the same model. For comparability across models between the same independent variable, the "estimate" provides a more accurate representation.

${ }^{6}$ Rerunning the model with all eight variables described above yields no differences in terms of significant factors and only minor alterations in the standardized regression weights. Notably, ethnic diversity and socio-economic
} 
The finding is consistent with homophily claims regarding a causal explanation of generalized trust. Students' first year experiences may very well be more tumultuous, and under such circumstances, diversity has a negative effect. However, it could be that perceived diversity changes after the first year leading classmates to see each other as adhering to a common set of characteristics or values. The parameters of similarity (described above) for homophily are flexible enough to incorporate a sense of shared values, beliefs, or simply experiences as a cohort.

The finding that students are influenced by their peers in the classroom is consistent with other studies that have explored group effects on attitudes. For example, Lazer et al. find "strong and consistent evidence of a social influence effect on changes in political views" $(2008,13)$. However, we also know that adolescent experience many new environments, all of which might exert influence on the extent to which they might be willing to place faith in strangers (Niemi and Sobieszek 1977). In an effort to test whether social influence effects are not exclusively a classroom phenomenon, we consider our data in terms of volunteer membership of our subjects. Rerunning our SEM analysis with group membership as an additional variable yields no significantly different findings. Belonging to a voluntary organization does not have a direct effect on generalized trust, and this is consistent with the literature (Stolle and Rochen 1998).

Table 3 shows the results of our SEM analysis when we split the sample between nonmembers and members of voluntary associations. Splitting the sample allows us to evaluate the indirect effect group membership on generalized trust. We hypothesized that the negative impact of diversity on generalized trust would be more pronounced among members compared to non-

diversity measured on the locality level were not significant suggesting the operative context is a smaller venue such as the classroom. 
members. Table 3 reports the results from the analysis, showing the earlier model rerun twice according to the membership attribute.

[Table 3 about here]

Like before, the strongest predictor of trust in the second time period is the trust a respondent expressed in the first. With regard to ethnic diversity, the earlier finding holds again for time 1 : ethnic diversity is not a correlate of generalized trust among all students, non-members and members alike. However, the acquired effect we saw in Table 2, ethnic diversity negatively associated with generalized trust in time2, only applies to non-members. For those who belong to voluntary associations, ethnic diversity has no statistical significance on generalized trust.

For socio-economic diversity, we see a different story. Both sides of the split sample show that income inequality is associated with lower levels of generalized trust in time 1. However, after the completion of a year in high school, the effect remains for the sub-sample who are members but loses statistical significance among the non-members. Thus, membership does have an indirect, and negative, effect on generalized trust that operates through income disparities.

\section{Discussion}

Our central purpose has been to evaluate the extent to which generalized trust - the faith we place in people we do not know_changes among high school students and consider factors that explain the variance. A cursory look at the panel data shows that levels of generalized trust are remarkably steady over time. Both as simple correlation and predictor in the SEM, we see that generalized trust is a stable trait. The finding is consistent with the literature that views generalized 
trust more as a cultural trait than one derived from experience, and by implication more highly variable. High school introduces a dramatic number of changes to students who are psychologically vulnerable and presumably malleable. High school would seem to be an ideal stimulus to spur change through experience, and yet we found very little. Although generalized trust is stable, it is not immutable and can be shaped by life experiences to an extent. We also found that the rate of change is not constant.

In considering factors that impact variance in generalized trust, we tested the impact of exposure to diversity, in the form of ethnicity and socio-economic standing. We found that ethnic diversity initially had no impact on generalized trust. However, at time 2 ethnic diversity in the classroom became negatively associated with generalized trust. The finding, although not conclusive, supports the idea that generalized trust is better fostered within relatively homogenous groups (Byrne 1971; McPherson and Smith-Lovin 1987). Among high school students, it is likely that this tendency reinforces social identity patterns among an age group whose identity patterns are often in flux, lending support to the theoretical approach of homophily (Tajfel and Turner 1986).

Uslaner states that "We can produce generalized trust by interacting with people who are different from ourselves" but continues that at the same time, people who put themselves in a position to interact with a diverse cultural context already have a substantial level of generalized trust $(2002,42)$. In our data, students had no choice to interact (or not) with diverse classmates, they were thrust into the context, and our findings are consistent with Uslaner's premise.

It is worth emphasizing that in our case, ethnic diversity refers to mostly to classmates that include the historic ethnic minorities of Romania, Hungarians and Roma. Unfortunately, our data 
does not allow us to dig deeper into the process through which this ethnic diversity becomes relevant for generalized trust.

Diversity in the form of income differences also produces negative effects on generalized trust. Our analysis shows that the across the two time periods, income inequality remained correlated with trust. The finding is consistent with a number of other studies (Bjørnskov 2007; Delhey and Newton 2005; Knack and Zak 2002; Uslaner 2002; Zak and Knack 2001). Socioeconomic diversity represents a broader outlook on life. Uslaner states that, "Generalized trusters are optimists who can believe they can control their lives" $(2002,112)$. If optimism and pessimism are operative, homophily in the form of homogeneity would seem to better apply.

A final observation regarding diversity is the importance of scope as well as context. The negative effect of diversity on generalized trust occurs within the context of a classroom. However, when we broaden the scope of the context to the level of community, we see no effect. Our analysis shows that neither ethnic diversity nor income inequality measured at the locality level has an effect on generalized trust. The result is consistent with similar studies that show, where ethnic diversity in the immediate surroundings produces a negative effect on generalized trust, the effect becomes insignificant in a wider contextual unit such as a neighborhood (e.g. Dinesen and Sønderskov 2012).

We also found that associational membership produces interaction effects, different for the two types of diversity considered. The negative effect of ethnic diversity on generalized trust holds for respondents who are not members of voluntary associations. Alternatively, the negative effect of income inequality holds for those who are members. The finding likely says something about the nature of the associations to which Romanian adolescents belong. McPherson and Smith-Lovin 
(1987) maintain that voluntary associations tend to attract individuals from similar backgrounds, and thus reinforce homophily tendencies.

Group members enjoy a level of solidarity that can minimize or eliminate the negative effect of its diversity. Although this may suggest a tendency toward homophily, non-ethnic demographic characteristics are equally likely to be the glue that holds the bonds described by proponents of similarity theory (Lazer et. al. 2008). A similar mechanism was found in a study of adults from the United States and Canada, where the negative effects of ethnic diversity are found to be mediated by social ties: the individuals who regularly talk with their neighbors are less influenced by the racial and ethnic character of their surroundings than people who lack such social interaction (Stolle, et al. 2008). Unfortunately, we do not have detailed information about the make-up of the groups to which respondents belong in terms of demographic and attitudinal characteristics. We also do not know the level of respondent activism in the groups to which they belong. Finally, we do not know the extent to which classmates belong to the same groups. It is possible that in some instances, social interaction among some classmates becomes intensified through extracurricular activities. Nevertheless, it seems reasonable to infer that generalized trust is a product of group dynamics in a classroom or association, and suggests that educational policy might be shaped in ways to positively influence the group dynamic.

\section{References:}

Alesina, A., La Ferrara, E., 2005. Ethnic diversity and economic performance. Journal of Economic Literature 43 (3), 762-800. 
Allport, G. W., 1954. The Nature of Prejudice. Reading, Addison Wesley (1979 reprint edition).

Andolina, M. W., Jenkins, K., Zukin, C., Keeter, S. 2003. Habits from home, lessons from school: influences on youth engagement. PS: Political Science and Politics 36 (2), 275-280.

Aumann, R. J., Dreze, J. H., 2005. When all is said and done, how should you play and what should you expect? CORE Discussion Papers 2005021, Université catholique de Louvain, Center for Operations Research and Econometrics (CORE).

Bădescu, G., 2003. Generalized trust and democratization in the post-communist societies. In: Bădescu, G., Uslaner, E. M. (Eds.), Social Capital and the Transition to Democracy. New York, Routledge, pp. 120-139.

Bădescu, G., Sum, P. E., Uslaner, E. M., 2004. Civil society development and democratic values in Romania and Moldova. Eastern European Politics and Society 18 (2), 316-341.

Bjørnskov, C., 2007. Determinants of generalized trust: a cross-country comparison. Public Choice $130(1), 1-21$.

Bobo, L. D., Tuan, M., 2006. Prejudice in Politics: Group Position, Public Opinion and the Wisconsin Treaty Rights Dispute. Cambridge, Harvard University Press.

Byrne, D., 1971. The Attraction Paradigm. New York, Academic Press.

Coleman, J. S., 1990. Foundations of Social Theory. Cambridge, Harvard University Press.

Colquitt, J. A., Scott, B. A., LePine, J. A., 2007. Trust, trustworthiness, and trust propensity: a meta-analytic test of their unique relationships with risk taking and job performance. Journal of Applied Psychology 92 (4), 909-927.

Delhey, J., Newton, K., 2005. Predicting cross-national levels of generalized trust: global pattern or Nordic exceptionalism? European Sociological Review 21 (4), 311-327.

Dinesen, P. T., 2010. Upbringing, early experiences of discrimination and social identity: explaining generalized trust among immigrants in Denmark. Scandinavian Political Studies 33 (1), 93-111.

Dinesen, P. T., 2011. Me and Jasmina down by the schoolyard: an analysis of the impact of ethnic diversity in school on the trust of schoolchildren. Social Science Research 40 (2), 572585 . 
Dinesen, P. T., Sønderskov, K. M., 2012. Trust in a time of increasing diversity: on the relationship between ethnic heterogeneity and generalized trust in Denmark from 1979 until today. Scandinavian Political Studies 35 (4), 273-294.

Dovidio, J. F., Gaertner, S. L., 1999. Reducing prejudice: combating intergroup biases. Current Directions in Psychological Science 8 (4), 101-105.

Forbes, H. D., 1997. Ethnic Conflict: Commerce, Culture, and the Contact Hypothesis. New Haven: Yale University Press.

Freitag, M., Traunmüller, R., 2009. Spheres of trust: an empirical analysis of the foundations of particularised and generalised trust. European Journal of Political Research 48 (6), 782-803.

Glanville, J. L., Paxton, P., 2007. How do we learn to trust? A confirmatory tetrad analysis of the sources of generalized trust. Social Psychology Quarterly 70 (3), 230-242.

Grovier, T., 1994. An epistemology of trust. International Journal of Moral Social Studies 8, 155174.

Jefferies, F. L., 2002. Subjective norms, dispositional trust, and initial trust development. Journal of Behavioral and Applied Management 3 (2), 129-139.

Jennings, K. M., Niemi, R. G., 1974. The Political Character of Adolescences. Princeton, Princeton University Press.

Jennings, K. M., Niemi, R. G., 1981. Generations and Politics. Princeton, Princeton University Press.

Knack, S., Zak, P. J., 2002. Building trust: public policy, interpersonal trust, and economic development. Supreme Court Economic Review 10: 91-107.

Kramer, R. M., 1999. Trust and distrust in organizations: emerging perspectives, enduring questions. Annual Review of Psychology 50, 569-598.

Lazarsfeld, P. F., Merton, R. K., 1954. Friendship as social process: a substantive and methodological analysis. In: Berger, M., Abel, T., Page, C. H. (Eds.), Freedom and Control in Modern Society. New York, Octagon Books, pp. 18-66. 
Lazer, D., Rubineau, B., Chetkovich, C., Katz, N., Neblo, M., 2008. Networks and political attitudes: structure, influence, and co-evolution. Harvard Kennedy School Faculty Research Working Paper Series RWP08-044, September.

Leigh, A., 2006. Trust, inequality and ethnic heterogeneity. Economic Record 82 (258), 268-280.

Letki, N., 2006. Investigating the roots of civic morality: trust, social capital, and institutional performance. Political Behavior 28 (4), 305-325.

Letki, N., Evans, G., 2005. Endogenizing social trust: democratization in East-Central Europe. British Journal of Political Science 35 (3), 515-529.

Marschall, M. J., Stolle, D., 2004. Race and the city: neighborhood context and the development of generalized trust. Political Behavior 26 (2), 125-153.

Mayer, R. C., Davis, J. H., Schoorman, F. D., 1995. An integrative model of organizational trust. Academy of Management Review 20, 709-734.

Messick, D. M., Kramer, R. M., 2001. Trust as a form of shallow morality. In: Cook, K. S. (Ed.), Trust in Society. New York, Russell Sage, pp. 89-117.

McPherson, M. J., Smith-Lovin, L., 1987. Homophily in voluntary organizations: status distance and the composition of face-to-face. American Sociological Review 52 (3), 370-379.

McPherson, M. J., Smith-Lovin, L., Cook, J. M., 2001. Birds of a feather: homophily in social networks. Annual Review of Sociology 27, 415-444.

Muller, E. N., Seligson, M. A., 1994. Civic culture and democracy: the question of causal relationships. American Political Science Review 88 (3), 635-652.

Nannestad, P., 2008. What have we learned about generalized trust, if anything? Annual Review of Political Science 11, 413-436.

Newton, K., 1999. Social capital and democracy in modern Europe. In: Van Deth, J., Maraffi, M., Newton, K., Whiteley, P. (Eds.), Social Capital and European Democracy. New York, Routledge, pp. 3-24.

Niemi, R. G., Sobieszek, B. I., 1977. Political socialization. Annual Review of Sociology 3, 209233. 
Öberg, P., Oskarsson, S., Svensson, T., 2009. Rethinking the relationship between diversity and trust. The Department of Government Studies in Political Economy and Welfare Working Paper Series 3, Uppsala Universitet.

Putnam, R. D., 1993. Making Democracy Work. Princeton, Princeton University Press.

Putnam, R. D., 2000. Bowling Alone: The Collapse and Revival of American Community. New York, Simon and Schuster.

Putnam, R. D., 2007. E. pluribus unum: diversity and community in the twenty-first century. The 2006 Johan Skytte Prize Lecture. Scandinavian Political Studies 30 (2), 137-174.

Reeskens, T., Hooghe, M. 2008. Cross-cultural measurement equivalence of generalized trust: evidence from the European Social Survey. Social Indicators Review 85, 515-532.

Rothstein, B., Uslaner, E. M., 2005. All for all: equality, corruption, and generalized trust. World Politics 58 (1), 41-72.

Stolle, D., Soroka, S., Johnston, R., 2008. When does diversity erode trust? Neighborhood diversity, interpersonal trust, and the mediating effect of social interactions. Political Studies 56 (1), 57-75.

Stolle, D., Rochen, T., 1998. Are all associations alike? Member diversity, associational type, and the creation of social capital. American Behavioral Scientist 42 (1), 47-65.

Sullivan, J. L., Transue, J. E., 1999. The psychological underpinnings of democracy: a selective review of research on political tolerance, interpersonal trust, and social capital. Annual Review of Psychology 50, 625-650.

Tajfel, H., Turner, J. C., 1986. The social identity theory of intergroup behavior. In: Worchel, S., Austin, W. G. (Eds.), Psychology of Intergroup Relations. Chicago, Nelson-Hall Publishers, pp. 7-24.

Uslaner, E. M., 2006. Does diversity drive down trust? The Fondazione Eni Enrico Mattei Note di Lavoro Series Index, Working Paper 69.

Uslaner, E. M., 2002. The Moral Foundations of Trust. Cambridge, Cambridge University Press.

Uslaner, E. M., 1999. Democracy and social capital. In: Warren, M. E. (Ed.), Democracy and Trust. Cambridge, Cambridge University Press, pp. 121-50. 
Voicu, B., 2005. Social capital: bonding or bridging Europe? In: Rusu, H., Voicu, B. (Eds.), EU Integration Process from EAST to EAST: Civil Society and Ethnic Minorities in a Changing World. Sibiu, RO: Psihomedia, pp. 77-98.

Völker, B., Flap, H., 2003. Communist societies, the velvet revolution, and weak ties: the case of East Germany. In: Bădescu, G., Uslaner, E. M. (Eds.), Social Capital and the Transition to Democracy. New York, Routledge, pp. 10-27.

Woolcock, M., 2001. The place of social capital in understanding social and economic outcomes. Isuma: Canadian Journal of Policy Research 2, 1-17.

Yamagishi, T., Yamagishi, M., 1994. Trust and commitment in the United States and Japan. Motivation and Emotion 18 (2), 129-166.

Zak, P. J., Knack, S., 2001. Trust and growth. Economic Journal 111 (470), 295-321.

Figure 1: Multilevel conceptual model of generalized trust (Trust ${ }_{1}=$ trust at time $1 ;$ Trust $_{2}=$ trust at time 2 ) 


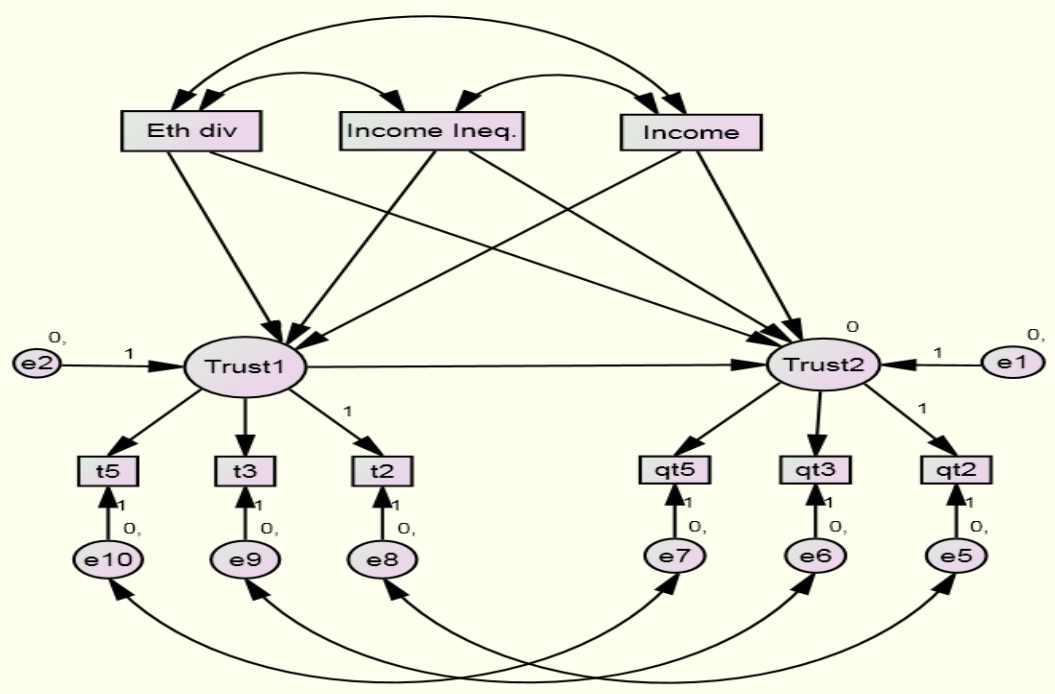

Table 1: Percentage of respondents who have very high or rather high trust in others

\begin{tabular}{|r|c|c|c|c|}
\hline & \multicolumn{3}{|l|}{ Trust in... } & $\mathrm{N}$ \\
\hline & strangers & $\begin{array}{c}\text { Other } \\
\text { religions }\end{array}$ & $\begin{array}{c}\text { other } \\
\text { ethnicities }\end{array}$ & \\
\hline & & & & \\
\hline time $_{1}$ & 6.0 & 37.6 & 33.6 & 1322 \\
\hline time $_{2}$ & 7.1 & 37.0 & 34.5 & 1247 \\
\hline
\end{tabular}

Table 2: Regression Weights in SEM on the subsample of Romanian students 


\begin{tabular}{|c|c|c|c|c|c|c|}
\hline & & & \multicolumn{4}{|c|}{ Standardized } \\
\hline & & & Estimate & S.E. & $\begin{array}{c}\text { Regression } \\
\text { Weights }\end{array}$ & p-value \\
\hline \begin{tabular}{|l|} 
Ethnic \\
diversity
\end{tabular} & $\rightarrow$ & Trust 1 & -.145 & .181 & .021 & .424 \\
\hline $\begin{array}{l}\text { Income } \\
\text { inequality }\end{array}$ & $\rightarrow$ & Trust 1 & -.532 & .096 & -.144 & $* * *$ \\
\hline Income & $\rightarrow$ & Trust 1 & .027 & .024 & .029 & .267 \\
\hline Trust 1 & $\rightarrow$ & Trust 2 & .180 & .017 & .596 & $* * *$ \\
\hline $\begin{array}{l}\text { Ethnic } \\
\text { diversity }\end{array}$ & $\rightarrow$ & Trust 2 & -.113 & .057 & .053 & $*$ \\
\hline $\begin{array}{l}\text { Income } \\
\text { inequality }\end{array}$ & $\rightarrow$ & Trust 2 & -.104 & .031 & -.093 & $* * *$ \\
\hline Income & $\rightarrow$ & Trust 2 & -.004 & .008 & -.014 & .599 \\
\hline Trust 1 & $\rightarrow$ & $\mathrm{t} 2 \_1$ & .308 & .025 & .326 & $* * *$ \\
\hline Trust 1 & $\rightarrow$ & $\mathrm{t} 3 \_1$ & .944 & .056 & .786 & $* * *$ \\
\hline Trust 1 & $\rightarrow$ & $\mathrm{t} 4 \_1$ & 1.000 & & .819 & \\
\hline Trust 2 & $\rightarrow$ & $\mathrm{t} 2 \_2$ & 1.000 & & .311 & \\
\hline Trust 2 & $\rightarrow$ & $\mathrm{t} 3 \_2$ & 3.172 & .266 & .815 & $* * *$ \\
\hline Trust 2 & $\rightarrow$ & $\mathrm{t} 4 \_2$ & 3.263 & .273 & .803 & $* * *$ \\
\hline
\end{tabular}

Table 3: Regression Weights in SEM with Group Membership as a grouping variable, on the subsample of Romanian students 


\begin{tabular}{|c|c|c|c|c|c|c|c|c|c|c|}
\hline & & & Estimate & S.E. & $\begin{array}{c}\text { Std. } \\
\text { regression } \\
\text { weights }\end{array}$ & $\mathrm{P}$ & Estimate & S.E. & $\begin{array}{c}\text { Std. } \\
\text { regression } \\
\text { weights }\end{array}$ & $\mathrm{P}$ \\
\hline $\begin{array}{l}\text { Ethnic } \\
\text { diversity }\end{array}$ & $\rightarrow$ & Trust 1 & -.029 & .227 & .005 & .900 & -.254 & .296 & .031 & .392 \\
\hline $\begin{array}{l}\text { Income } \\
\text { inequality }\end{array}$ & $\rightarrow$ & Trust 1 & -.369 & .126 & -.107 & $* *$ & -.730 & .146 & -.185 & $* * *$ \\
\hline Income & $\rightarrow$ & Trust 1 & .027 & .033 & .031 & .404 & .023 & .035 & .024 & .511 \\
\hline Trust 1 & $\rightarrow$ & Trust 2 & .222 & .033 & .541 & $* * *$ & .166 & .021 & .626 & $* * *$ \\
\hline $\begin{array}{l}\text { Ethnic } \\
\text { diversity }\end{array}$ & $\rightarrow$ & Trust 2 & -.293 & .131 & .114 & $*$ & -.034 & .068 & .016 & .616 \\
\hline $\begin{array}{l}\text { Income } \\
\text { inequality }\end{array}$ & $\rightarrow$ & Trust 2 & -.125 & .072 & -.089 & .080 & -.095 & .035 & -.091 & $* *$ \\
\hline Income & $\rightarrow$ & Trust 2 & .009 & .018 & .024 & .632 & -.009 & .008 & -.036 & .273 \\
\hline Trust 1 & $\rightarrow$ & $\mathrm{t} 2 \_1$ & .322 & .035 & .335 & $* * *$ & .298 & .035 & .318 & $* * *$ \\
\hline Trust 1 & $\rightarrow$ & t3_1 & 1.017 & .082 & .835 & $* * *$ & .890 & .075 & .747 & *** \\
\hline Trust 1 & $\rightarrow$ & $\mathrm{t} 4 \_1$ & 1.000 & & .815 & & 1.000 & & .818 & \\
\hline Trust 2 & $\rightarrow$ & $\mathrm{t} 2 \_2$ & 1.000 & & .411 & & 1.000 & & .277 & \\
\hline Trust 2 & $\rightarrow$ & t3_2 & 2.665 & .306 & .895 & $* * *$ & 3.401 & .383 & .780 & *** \\
\hline Trust 2 & $\rightarrow$ & $\mathrm{t} 4 \_2$ & 2.578 & .287 & .831 & $* * *$ & 3.608 & .412 & .792 & $* * *$ \\
\hline
\end{tabular}

Non-members: CFI $=0.989$; TLI $=0.973$; RMSEA $=0.026$

Members: CFI $=0.987$; TLI $=0.963 ;$ RMSEA $=0.029$

$*=\mathrm{p}<.05 ; * *=\mathrm{p}<.01 ; * * *=\mathrm{p}<.001$ 